\title{
Failure Behavior of Thermal Barrier Coatings on Cylindrical Superalloy Tube Under Thermomechanical Fatigue
}

\section{Zhubing $C H E N^{1,2) \dagger}$, Zhongguang WANG ${ }^{2}$ and Shijie $Z H U^{3)}$}

1) Shenyang Aeroengine Research Institute, Aviation Industry Corporation of China, Shenyang 110015, China

2) Shenyang National Laboratory for Materials Science, Institute of Metal Research, Chinese Academy of Sciences, Shenyang 110016, China

3) Department of Intelligent Mechanical Engineering, Fukuoka Institute of Technology, Higashi-ku, Fukuoka, 811-0295, Japan

[Manuscript received 21 January 2013, in revised form 1 April 2013]

(C) The Chinese Society for Metals and Springer-Verlag Berlin Heidelberg

\begin{abstract}
Failure behavior of thermal barrier coatings on cylindrical superalloy tube was investigated under thermomechanical fatigue (TMF). Two types of TMF tests, i.e. in phase (IP) and out of phase (OP), were performed in the temperature range of $450-850^{\circ} \mathrm{C}$. All tests were carried out under mechanical strain control at a given period of $300 \mathrm{~s}$. The bond coat NiCrA1Y was produced by high velocity oxygen fuel (HVOF), and the top coat $7 \% \mathrm{Y}_{2} \mathrm{O}_{3}-\mathrm{ZrO}_{2}$ was deposited by air plasma spraying (APS). The testing results showed that the OP TMF life was longer than the IP TMF one under the same mechanical strain amplitude. Observations of the fractured specimens revealed that the interface damage and cracking behavior in the two phasing conditions were different. In OP loading, the top coat was cracked and detached from the bond coat while no spallation was found in the IP loading.
\end{abstract}

KEY WORDS: Thermal barrier coating; Air plasma spraying; High velocity oxygen fuel; Thermomechanical fatigue

\section{Introduction}

Thermal barrier coatings (TBCs) have been widely used to hot section parts of the gas turbines engines to provide thermal protection to the metallic components ${ }^{[1-3]}$. They offer potential to lower the temperature of the metal substrate and thus to result in increasing power efficiency and reducing the greenhouse gas emission. A TBC component is a multilayer system consisting of a superalloy substrate, a bond coat and a ceramic top coat which is $\mathrm{ZrO}_{2}$ stabilized with (6-8) wt\% $\mathrm{Y}_{2} \mathrm{O}_{3}{ }^{[4]}$.

The bond coat is usually the MCrAlY overlay coating (where $M$ is $\mathrm{Ni}$, Co, Fe, or a combination of these elements), which can be produced by thermal spraying technique, by sputtering or evaporation; however, for practical applications, thermal sprayed

\footnotetext{
† Corresponding author. Ph.D.; Tel.: +86 24 24281653; Fax: +86 24 24285673; E-mail: chenzhb731@163.com (Zhubing CHEN)
}

DOI: $10.1007 / \mathrm{s} 40195-013-0028-9$ coatings are normally preferred ${ }^{[5]}$. The quality of the traditional air plasma spraying (APS) coating is low because of high pore density and oxidation, while the cost of the vacuum plasma spraying (VPS) coating is high; the coating prepared by high velocity oxygen fuel (HVOF) has dense microstructure, high adhesive strength and low cost, therefore HVOF thermal spray process is a promising technique for forming the bond coat $^{[6]}$.

Hot section components undergo severe cyclic thermal and mechanical load during service and thus thermomechanical fatigue (TMF) provides a closer simulation of the actual strain-temperature cycle that coating and substrate experience in an engine environment $^{[7]}$. Therefore, TMF tests are useful for evaluating the service lifetime of TBC systems, as well as for mechanism-based life modeling approaches. However, only a few publications are available in the open literature dealing with TMF testing of TBC systems $^{[8-14]}$. The main reason for the limited number of publications is the demanding of powerful heating technique for the TBC system, where the top coat 
has low thermal conductivity, and fast cooling device.

The primary aim of this paper is to present the results concerning the TMF lifetime and failure behavior of a TBC system consisting of a Ni-based superalloy substrate, a NiCrA1Y bond coat sprayed by $\mathrm{HVOF}$ and a $\mathrm{Y}_{2} \mathrm{O}_{3}-\mathrm{ZrO}_{2}$ top coat prepared by APS, with emphasis of the influence of the phase difference between the applied thermal and mechanical loading.

\section{Experimental}

The conventionally cast Ni-based superalloy M963 was used as a substrate, which is a candidate material for vanes and blades in gas turbine engine. Its chemical composition (in wt.\%) was C 0.15 , Cr 8.89, Al 6.00, Ti 2.55, Mo 1.64, W 10.1, Co 10.0, Nb 1.10, Zr 0.03, B 0.03, Ce 0.02, Y 0.01 and Ni balance. Before machining the specimens were solution-treated at $1210^{\circ} \mathrm{C}$ for $4 \mathrm{~h}$ and followed by air cooling. Cylindrical tube specimens were machined with a total length of $135 \mathrm{~mm}$, an internal diameter of $7 \mathrm{~mm}$ and in the gauge length an external diameter of $10 \mathrm{~mm}$. The substrate was coated with a Ni-25Cr-5Al-0.5Y bond coat with a normal thickness of $130 \mu \mathrm{m}$ by HVOF spray. $7 \% \mathrm{Y}_{2} \mathrm{O}_{3}-\mathrm{ZrO}_{2}$ top coat of $250 \mu \mathrm{m}$ thick was prepared by APS. The HVOF equipment is JP-5000HP/HVOF of Hobart Tafa, and the spray parameters have been described elsewhere ${ }^{[15]}$. The top coat was produced by METCO 7M under the following conditions: argon gas atmosphere of $0.4-0.6 \mathrm{MPa}$, voltage of $45^{-}$ $65 \mathrm{~V}$, current of 500-550 A, spraying distance of 70$120 \mathrm{~mm}$.

The TMF tests were performed on a MTS810 closed-loop servohydraulic testing machine with computer control. A radiation furnace powered by four cylindrical quartz lamps, each with a maximal power of $2.5 \mathrm{~kW}$, was used for heating. The radiation of the quartz lamps was focused onto the specimen with elliptical mirrors. The outer surface temperature of the specimen, which was controlled by the power output of the lamps, was measured with a thermocouple enlacing the specimen. This furnace was similar to the one described by DLR group ${ }^{[8,16-19]}$. Cooling was achieved by compressed air flowing through the specimen tube. Axial strain measurements were obtained using a self-supporting extensometer which had a gauge length of $23 \mathrm{~mm}$ and was supported with ceramic rods. A triangle waveform was used for both thermal cycling and mechanical cycling. Two kinds of TMF tests were designed: in phase (IP) where the maximum mechanical strain coincided with the maximum temperature and out of phase (OP) where the maximum mechanical strain was attained at the minimum temperature. The TMF tests were carried out in the temperature range of $450-850{ }^{\circ} \mathrm{C}$ with a cyclic period of $300 \mathrm{~s}$ under mechanical strain control. The mechanical strain amplitudes were varying from $0.35 \%$ to $0.5 \%$ with a strain ratio of -1 .

After the TMF tests, all specimens, besides the de-

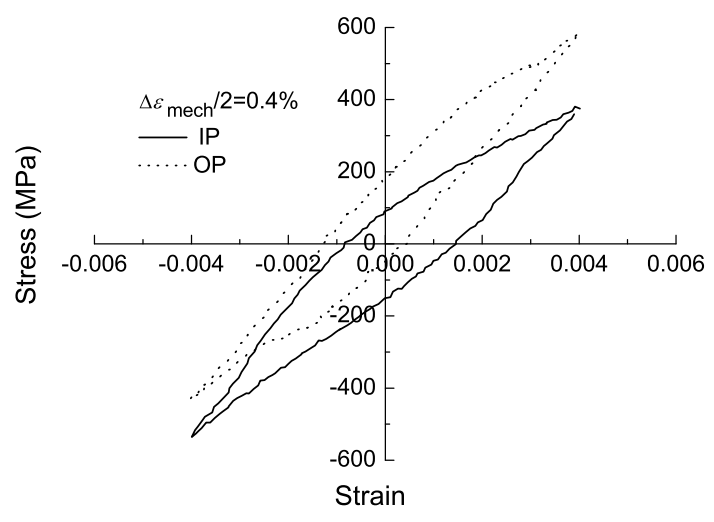

Fig. 1 Middle-life hysteresis loops for IP and OP TMF at $\Delta \varepsilon_{\text {mech }} / 2=0.4 \%$

tached side of the top coat, were recorded by a digital camera. Then, fracture surfaces and metallographically prepared longitudinal sections were observed in a scanning electron microscope (SEM).

\section{Results and Discussion}

\subsection{Cyclic deformation and fatigue life}

Fig. 1 shows the typical stress-mechanical strain hysteresis loops of IP TMF and OP TMF at mechanical strain amplitude of $0.4 \%$. It can be seen that the maximum and minimum stresses of the each hysteresis loop are unsymmetrical. In IP TMF, the value of the maximum stress is lower than that of the minimum one, while it is just contrary under OP TMF condition, and the value of the maximum is higher.

Information obtained from cyclic stress response behavior is important to understand the cyclic deformation behavior and damage mechanism in TMF tests. Cyclic stress response behavior at mechanical strain amplitude of $0.4 \%$ is shown in Fig. 2. The mean stress $\left(\sigma_{\mathrm{m}}\right)$, as well as maximum stress $\left(\sigma_{\max }\right)$ and minimum stress $\left(\sigma_{\min }\right)$ are plotted as a function of the number of cycles $(N)$. In the tensile stress cycles, the stress gradually descends in IP TMF while it rises under OP TMF condition; in the compressive stress cycles, the tendency of the stress is just adverse. As a result, the mean stress is compressive in IP TMF and tensile in OP TMF. This result accords with the information of the hysteresis loops.

Mechanical strain amplitude of IP and OP TMF are plotted as a function of fatigue life as shown in Fig. 3. It can be seen that fatigue life decreases with an increase in mechanical strain amplitude. Under the same mechanical strain amplitude, OP TMF exhibits longer fatigue life than IP TMF. This result is opposite to the result that the life in the IP TMF is longer ${ }^{[9,14]}$. Generally, OP TMF is found to be the most damaging factor on the leading edge of a gas turbine. However, the present result corresponds to the result reported by Wright ${ }^{[11]}$. That is, in IP TMF cycles, applied mechanical strain as well as the ther- 


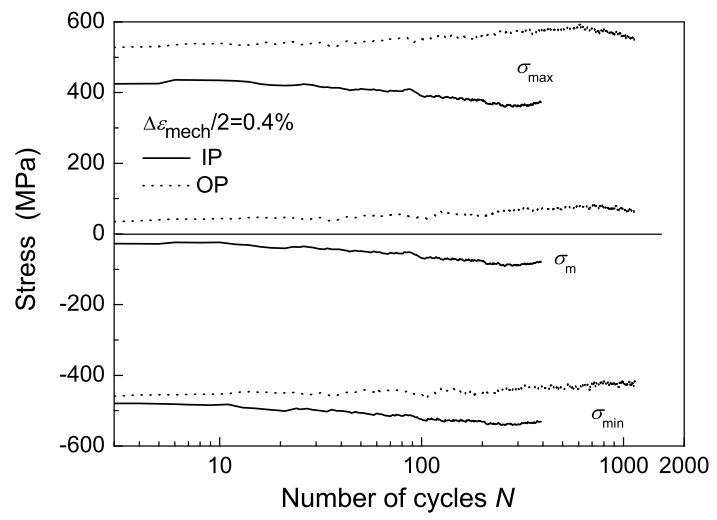

Fig. 2 Cyclic stress response curves for IP and OP TMF at $\Delta \varepsilon_{\mathrm{mech}} / 2=0.4 \%$

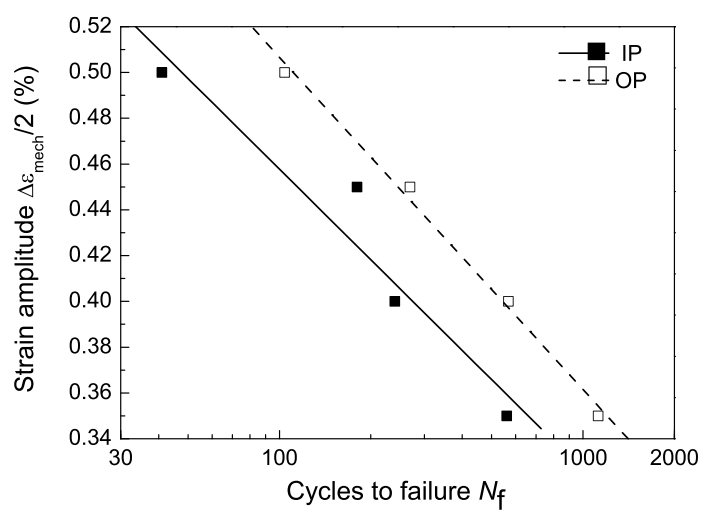

Fig. 3 Mechanical strain amplitude as a function of cycles to failure

mal strain produced larger total strain level, and lowered the lifetime.

\subsection{Morphology observation}

The macroscopic photos of failed TBC specimens at $\Delta \varepsilon_{\text {mech }} / 2=0.45 \%$ are shown in Fig. 4. From Fig. 4(a) it can be seen that the specimen failed in the gauge in IP TMF test. However, the failure behavior of the specimen under OP TMF condition is more complex. The top coat was detached from the bond coat though the specimen also failed in the gauge. The spallation behavior was also reported by Wright ${ }^{[11]}$. In his research, a "tent-like" lifting of the top coating layer, spalls with cracking in both the axial and circumferential directions of the top coat, and irregularly shaped spalls were found. However, the coating with "tent-like" behavior was not found in this research.

The fractograph of failed specimen at $\Delta \varepsilon_{\text {mech }} / 2=0.45 \%$ under IP TMF condition is shown in Fig. 5(a). There is no crack initiation site and interface delamination. The phenomenon is different from that of the OP TMF tests. The fracture surface at $\Delta \varepsilon_{\text {mech }} / 2=0.35 \%$ is shown in Fig. $5(\mathrm{~b})$. It can be seen that the top coat is detached from the bond coat, and the distance between the bond coat and the top coat is very large. The photo also exhibits delamination of the bond coat from the substrate. These results accord with information of the macroscopic photos.

The longitudinal sections close to fracture surface are shown in Fig. 6. No obvious delamination and cracking are found in the IP TMF tests at $\Delta \varepsilon_{\text {mech }} / 2=0.45 \%$ as shown in Fig. 6(a). The crack vertical to the stress axial was detected in the top coat under OP TMF condition at $\Delta \varepsilon_{\text {mech }} / 2=0.5 \%$ (see Fig. 6(b)). Then the crack did not penetrate to the bond coat but deflected upon reaching the interface between the bond coat and top coat. This phenomenon corresponds to the macro-observation that the top coat was detached from the bond coat.

\subsection{Strain analysis of the coating and discussion}

The strain analysis of the coating was done for understanding the lifetime, coating cracking and spallation behavior under the different phases between the thermal and mechanical loading. Besides the applied mechanical strain, there is a thermal mismatch strain arising from difference in thermal expansion coefficient between the coating and substrate during TMF testing, as the sketch shown in Fig. $7^{[11]}$. Thus the
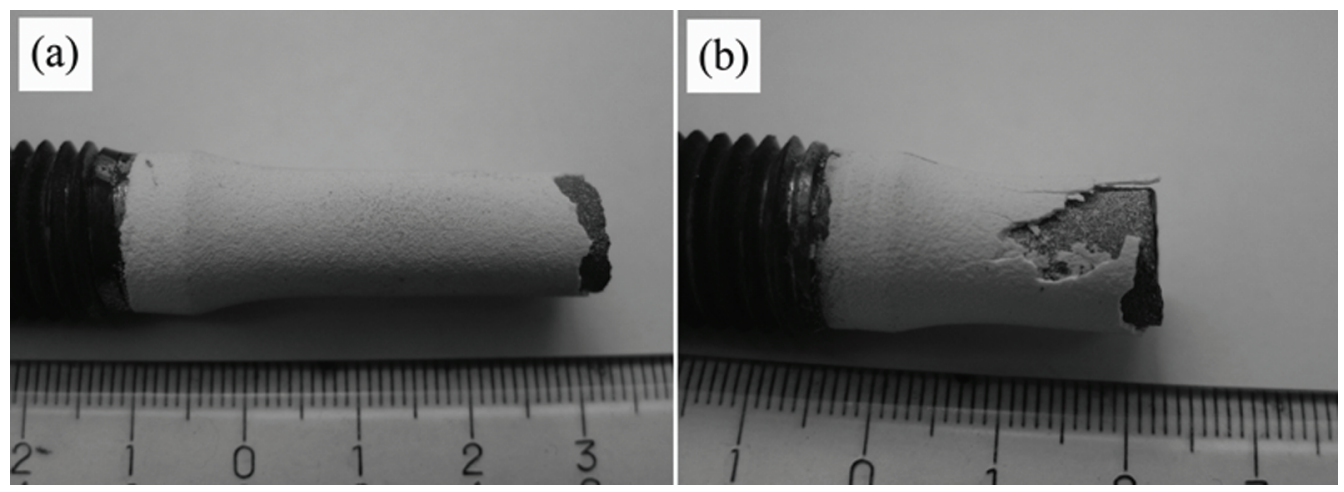

Fig. 4 Macroscopic photos of failed specimen at $\Delta \varepsilon_{\text {mech }} / 2=0.45 \%$ under IP TMF (a) and OP TMF (b) 

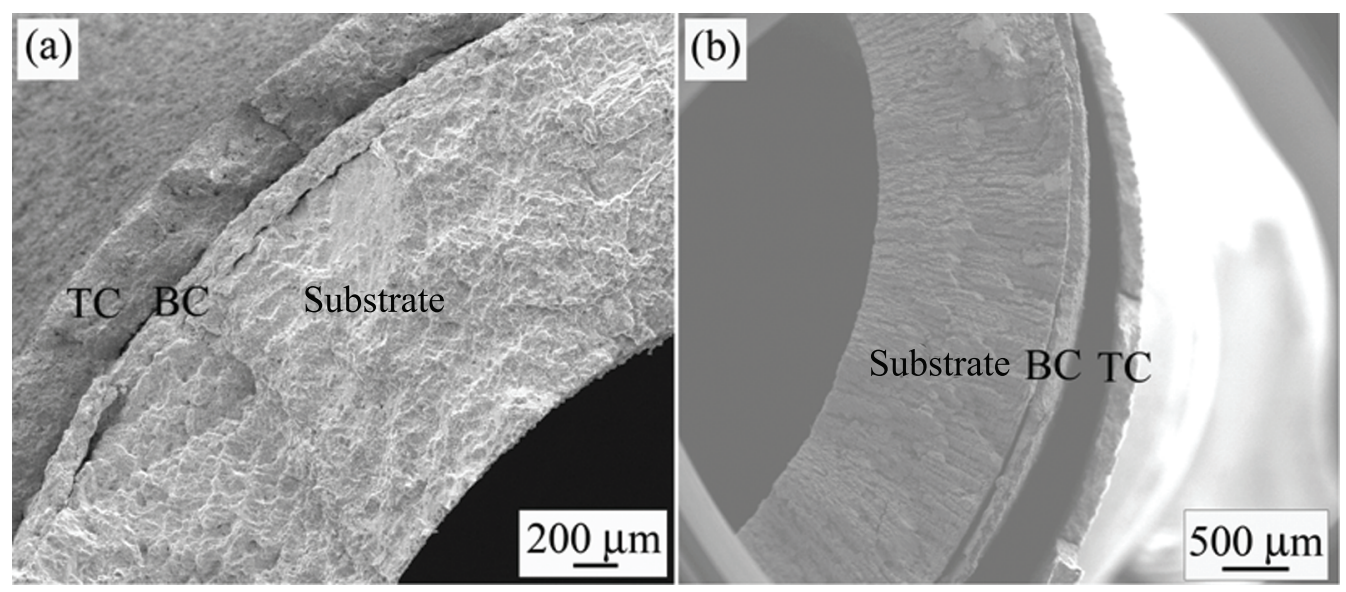

Fig. 5 Fractographs of failed specimen at IP TMF, $\Delta \varepsilon_{\text {mech }} / 2=0.45 \%$ (a) and OP TMF, $\Delta \varepsilon_{\text {mech }} / 2=0.35 \%$ (b) (TC, top coat, BC, bond coat)

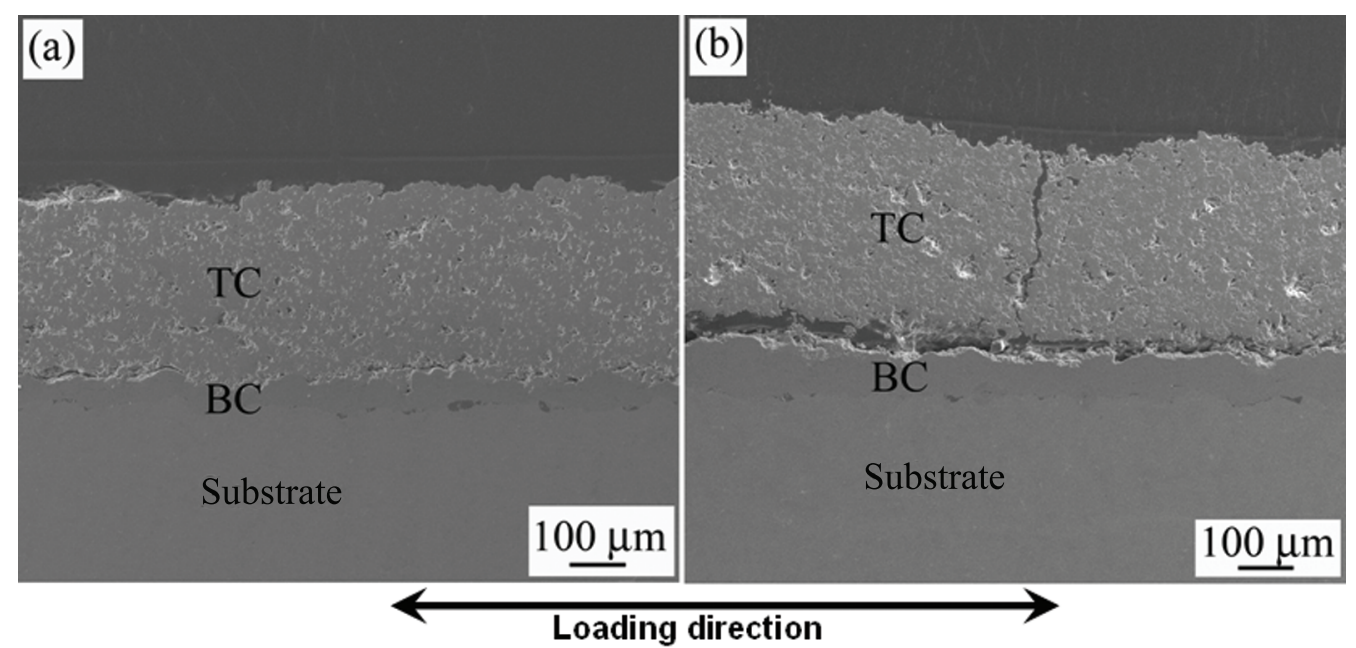

Fig. 6 Micrographs of longitudinal section of failed specimen at IP TMF, $\Delta \varepsilon_{\text {mech }} / 2=0.45 \%$ (a) and OP TMF, $\Delta \varepsilon_{\text {mech }} / 2=0.5 \%(\mathrm{~b})$

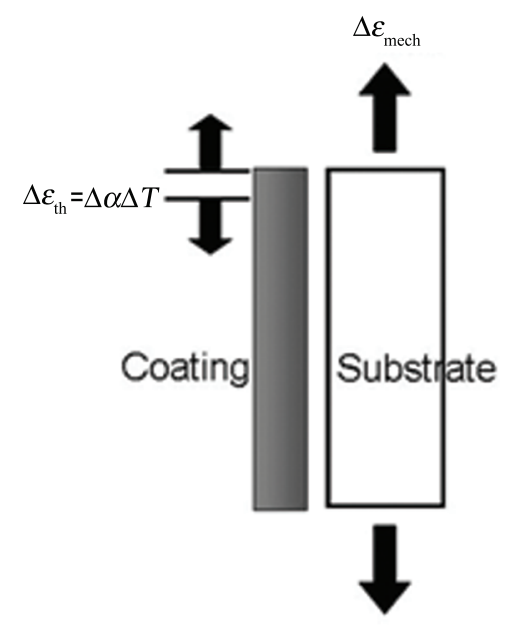

Fig. 7 Sketch of strain analysis of coated specimen

total strain, $\Delta \varepsilon_{\text {tot }}$, being applied to the coating is the sum of both the applied mechanical strain, $\Delta \varepsilon_{\text {mech }}$, and thermal mismatch strain, $\Delta \varepsilon_{\mathrm{th}}$ :

$$
\Delta \varepsilon_{\text {tot }}=\Delta \varepsilon_{\text {mech }}+\Delta \varepsilon_{\text {th }}
$$

Since the TBC failure process is observed to be in the oxide or in the top coat closing the interface with the oxide, the total strain in the oxide is thought to control the coating damage and failure behavior. The thermal expansion of the oxide is taken to be that of pure alumina ${ }^{[20]}$. The thermal strain $\varepsilon_{\text {th }}$ of the oxide or the substrate is calculated as follow:

$$
\varepsilon_{\mathrm{th}}=\alpha \Delta T
$$

where $\alpha$ is the mean coefficient of thermal expansion in the temperature range of $\Delta T$.

Generally the specimen fails under the action of the maximum tensile strain which corresponds to the maximum and minimum temperature for IP TMF or OP TMF, respectively. Therefore, the maximum thermal mismatch strain, $\Delta \varepsilon_{\text {th }}$, is calculated as difference in free thermal strain between the oxide and 
the superalloy M963 below:

$\Delta \varepsilon_{\text {th }}=\alpha^{\mathrm{M} 963}\left(T_{\max }-T_{\text {middle }}\right)-\alpha^{\mathrm{Al}_{2} \mathrm{O}_{3}}\left(T_{\max }-T_{\text {middle }}\right)$

$\Delta \varepsilon_{\text {th }}=\alpha^{\mathrm{M} 963}\left(T_{\min }-T_{\text {middle }}\right)-\alpha^{\mathrm{Al}_{2} \mathrm{O}_{3}}\left(T_{\text {min }}-T_{\text {middle }}\right)$

Eq. (3a) applies to the IP TMF test and the maximum thermal mismatch strain range arrives at the maximum temperature $850{ }^{\circ} \mathrm{C}$. Eq. (3b) applies to the $\mathrm{OP}$ TMF test and the maximum thermal mismatch strain range obtains at the minimum temperature $450{ }^{\circ} \mathrm{C}$, where $T_{\text {middle }}$ is for the middle temperature of the test which is $650{ }^{\circ} \mathrm{C}$ in this experiment.

During IP TMF cycling, the temperature increases from the middle to the maximum, and the thermal mismatch strain of the oxide is tensile, leading to a positive strain in Eq. (3a). This thermal strain adds to the applied mechanical strain, producing a larger total strain range. During OP TMF cycling, the temperature decreases from the middle to the minimum, and the thermal mismatch strain of the oxide is compressive, leading to a negative strain in Eq. (3b), which is of opposite sign to the applied mechanical strain. Therefore, when the two add up, the total strain gets a lower strain range. This total strain is thought to be the determinate factor of the coating life because it directly relates to the stress of the coating. The magnitude of the total strain under IP TMF condition is larger so that the life of the coating is shorter.

The strain in the axial direction has been analyzed before; however, the state of strain of the specimen is actually biaxial, since the thermal mismatch strain acts in all directions equally, and there is a transverse component of the applied mechanical strain. Therefore, the total strain in the transverse direction is:

$$
\Delta \varepsilon_{\text {tot }}=-\nu \Delta \varepsilon_{\text {mech }}+\Delta \varepsilon_{\text {th }}
$$

where $\nu$ is the Poisson's ratio.

For IP TMF cycling, the transverse mechanical strain is compressive, while the thermal mismatch strain is tensile and they act with opposite signs. Thus the total transverse strain range is smaller. For OP TMF cycling, the transverse mechanical strain is compressive, and the thermal mismatch strain is also compressive. Therefore, when the two add up, the total transverse strain gets larger. It is thought that this larger compressive transverse strain causes the top coat to buckle and then lead to spallation of the top coat, which is validated by the observation as the macroscopic photos.

\section{Conclusions}

(1) The TMF life decreased with an increase in the mechanical strain amplitude. Under the same mechanical strain amplitude the OP TMF life was longer than the IP TMF one.
(2) The deformation behavior was unsymmetrical and the average stress was compressive in the IP TMF tests while it was tensile in OP TMF tests.

(3) The interface damage and cracking behavior were different in the two phase conditions because of different actual total strain.

\section{Acknowledgement}

This work was financially supported by the Center for Interfacial Materials, Shenyang National Laboratory for Materials Science, Institute of Metal Research, Chinese Academy of Sciences.

\section{REFERENCES}

[1] W.J. Brindley and R.A. Miller, Adv. Mater. Process. 136 (1989) 29.

[2] R.A. Miller, Surf. Coat. Technol. 30 (1987) 1.

[3] N.P. Padture, M. Gell and E.H. Jordan, Science 296 (2002) 280

[4] A.G. Evans, D.R. Mumm, J.W. Hutchinson, G.H. Meier and F.S. Pettit, Prog. Mater. Sci. 46 (2001) 505.

[5] M. Di Ferdinando, A. Fossati, A. Lavacchi, U. Bardi, F. Borgioli, C. Borri, C. Giolli and A. Scrivani, Surf. Coat. Technol. 204 (2010) 2499.

[6] H.J. Jang, D.H. Park, Y.G. Jung, J.C. Jang, S.C. Choi and U. Paik, Surf. Coat. Technol. 200 (2006) 4355.

[7] Z.W. Huang, Z.G. Wang, S.J. Zhu, F.H. Yuan and F.G. Wang, Mater. Sci. Eng. A 432 (2006) 308.

[8] B. Baufeld, M. Bartsch, S. Dalkili and M. Heinzelmann, Surf. Coat. Technol. 200 (2005) 1282.

[9] B. Baufeld, E. Tzimas, P. Hühner, H. M llejans, S. D. Peteves and P. Moretto, Scr. Mater. 45 (2001) 859.

[10] B. Baufeld, E. Tzimas, H. Müllejans, S. Peteves, J. Bressers and W. Stamm, Mater. Sci. Eng. A 315 (2001) 231.

[11] P. Kennard Wright, Mater. Sci. Eng. A 245 (1998) 191.

[12] A. Peichl, T. Beck and O. Vöhringer, Surf. Coat. Technol. 162 (2003) 113.

[13] E. Tzimas, H. Müllejans, S. D. Peteves, J. Bressers and W. Stamm, Acta Mater. 48 (2000) 4699.

[14] Z.B. Chen, Z.G. Wang and S.J. Zhu, Mater. Sci. Eng. A 528 (2011) 8396.

[15] F.H. Yuan, Z.X. Chen, Z.W. Huang, Z.G. Wang and S.J. Zhu, Corros. Sci. 50 (2008) 1608.

[16] M. Bartsch, B. Baufeld, S. Dalkili, L. Chernova and M. Heinzelmann, Int. J. Fatigue 30 (2008) 211.

[17] M. Bartsch, G. Marci, K. Mull and C. Sick, Adv. Eng. Mater. 1 (1999) 127.

[18] B. Baufeld, M. Bartsch, P. Brož and M. Schmücker, Mater. Sci. Eng. A 384 (2004) 162.

[19] B. Baufeld, M. Bartsch and M. Heinzelmann, Int. J. Fatigue 30 (2008) 219.

[20] C. Zhou, N. Wang and H. Xu, Mater. Sci. Eng. A 452-453 (2007) 569. 